BRIEF REPORT

\title{
Reducing social inequalities in smoking: can evidence inform policy? A pilot study
}

D Ogilvie, M Petticrew

Tobacco Control 2004;13:129-131. doi: 10.1136/tc.2003.003962

Objective: To assess the potential contribution of evidence from existing systematic reviews of effectiveness to answering the question: what works in reducing social inequalities in smoking?

Data source: The Cochrane Library (2002/4).

Study selection: Systematic reviews of the effectiveness of community based tobacco control interventions, and all the primary studies included in one of these reviews.

Data extraction: Reviews and primary studies were assessed for intent to assess the social distribution of intervention effects, information about the social inclusiveness or targeting of interventions, baseline sociodemographic data collected on participants, and estimates of effect size stratified by sociodemographic variables.

Data synthesis: Only one review aimed to examine outcomes stratified by sex, age or socioeconomic status, and these aims were only achieved with respect to sex. Sociodemographic data about participants were frequently collected in primary studies, but not used to compare intervention effects between social groups.

Conclusions: There may be scope for using existing research more effectively to contribute to evidence based policy to reduce social inequalities in smoking-by explicitly seeking stratified outcome data in new systematic reviews, by reanalysing original datasets, and/or by meta-analysis of individual participant data.

l: n many countries, smoking is persistently associated with social disadvantage and reducing social inequalities in smoking has become a political priority. Is there any evidence that current tobacco control policies will help to achieve this? Simply applying or intensifying interventions known to reduce overall smoking behaviour will not necessarily be effective among disadvantaged groups. ${ }^{1}$ It is, however, equally plausible that other policies and interventions could help to reduce inequalities. ${ }^{2}$

Mackenbach and Bakker have assembled evidence of successful interventions to reduce health inequalities in a recent book. ${ }^{3}$ In this book, Platt and colleagues have argued that by concentrating on reducing overall tobacco consumption, we are missing the chance to tackle health inequalities. ${ }^{4}$ After reviewing a selection of intervention studies and stratifying them according to whether or not they were targeted on, or effective in, disadvantaged groups, they concluded that there was little direct evidence to suggest that either demand- or supply-side measures were likely to affect inequalities in tobacco use. Their conclusions echo those of the Acheson report on inequalities and health produced for the UK government in 1998. ${ }^{1}$

What can be done about the lack of evidence to inform policy in this area? Designing and conducting new primary research takes time. Systematic reviews are increasingly viewed as the most robust source of evidence of the effectiveness of public health interventions. We investigated the potential for using existing systematic reviews in the Cochrane Library to answer the question: what works in reducing social inequalities in smoking?

\section{METHODS}

We searched the Cochrane Tobacco Addictions Group reviews in the Cochrane Library $(2002 / 4)^{5}$ for completed reviews of the effectiveness of community based tobacco control interventions. We analysed the content of each report for:

- evidence that the social distribution of intervention effects had been considered

- information about the social inclusiveness or targeting of the interventions

- information about the social composition of the target or study population

- information about baseline sociodemographic data collected on participants

- stratification of estimates of effect size by sociodemographic variables.

We then chose one of the Cochrane reviews (Community interventions for preventing smoking in young people $)^{6}$ for more detailed analysis, in which we sought the same information from all the primary studies included in that review. We chose the topic of prevention in young people because smoking is a habit that is often established early in life, its uptake is associated with socioeconomic status, and the review on that topic contained a suitable number of primary studies for a pilot analysis. Although it can be difficult to measure socioeconomic status in young people, we wished to establish the potential usefulness of primary studies in this area rather than simply assuming that no evidence would be available.

\section{RESULTS}

\section{Evidence from systematic reviews}

We found six relevant completed Cochrane reviews. ${ }^{6-11}$ The reviews covered preventing young people from smoking through interventions in communities, schools and the mass media and through tobacco retailers, and reducing adult smoking through interventions in communities and public places.

Most reviews included some studies of interventions targeted on higher risk groups, such as girls, inner city communities, ethnic minorities, or the children of parents with low incomes or low levels of educational attainment.

In five of the six reviews we found no evidence of any intention to consider the social distribution of effects, and no attempt to stratify summary outcome measures by any sociodemographic variable. ${ }^{6-11}$ 


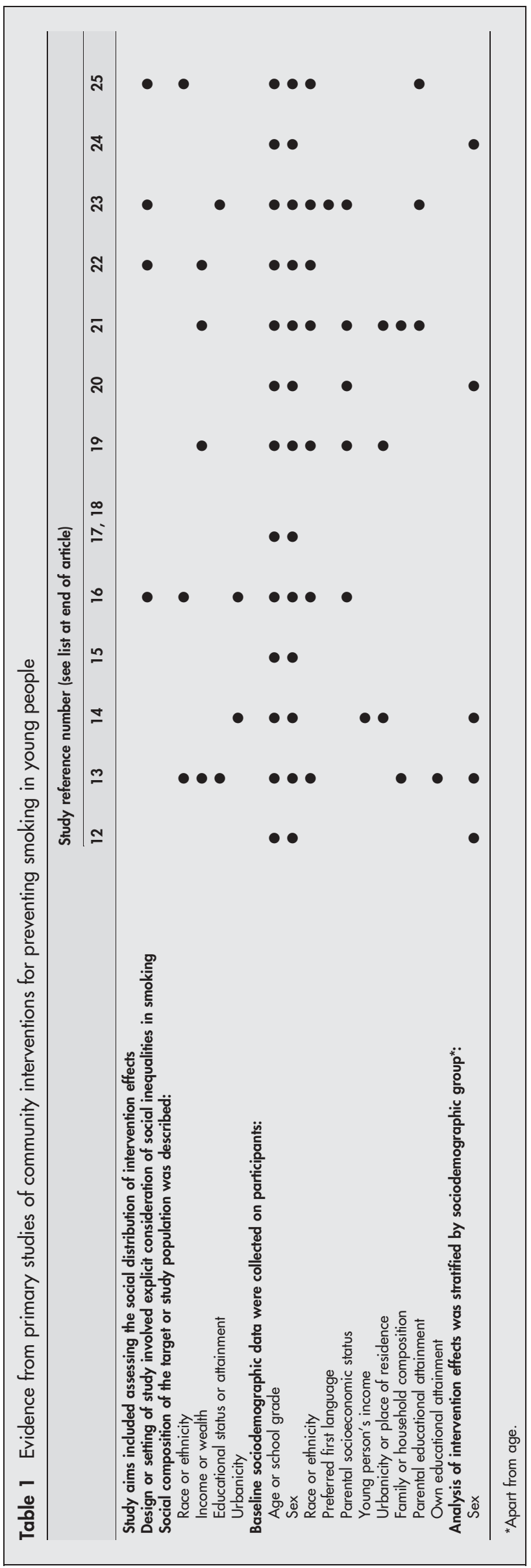

One review (Community interventions for reducing smoking among adults) did specifically aim to examine outcomes stratified by sex, age and socioeconomic status "where available", but these aims were only achieved with respect to sex. ${ }^{7}$ Only changes in smoking prevalence could be pooled across studies: the estimated decline in smoking prevalence was greater in women than men.

The reviewers also mentioned other relevant findings from the primary studies. Three studies had reported differences in process measures between social groups. Two had reported differences in outcome measures: one found that quit rate was particularly increased among younger women and women with low incomes; another found that smoking prevalence fell among whites, women under 35, and those with higher incomes, but not among men or African Americans.

The most recent Cochrane review (School-based programmes for preventing smoking) included 76 studies, of which 10 reported outcomes stratified by sex. ${ }^{11}$ Those studies whose results suggested greater effectiveness among girls were balanced by studies suggesting greater effectiveness among boys.

Evidence from primary studies of community interventions for preventing smoking in young people Thirteen studies (14 papers) were included in this review (table 1). ${ }^{12-25}$ None had aimed to assess the social distribution of intervention effects, although social inequalities in smoking had been considered in the design of four studies. In three of these cases, the intervention had been targeted on higher risk groups: a black inner city community, ${ }^{16}$ those attending continuation high schools, ${ }^{23}$ or those attending clubs in deprived communities. ${ }^{22}$

Most studies gave little or no detailed information about the social composition of the target populations. One study provided data on the distribution of income, ethnicity, and educational attainment. ${ }^{13}$

Baseline data on age and sex had been collected on participants in all the studies. A variety of other socioeconomic variables had also been included (table 1). Most studies had considered these variables as potential confounders, using them either to match participants or communities with controls or as covariates in a multivariate analysis of intervention effects. Five studies reported outcomes stratified by sex. No study reported outcomes stratified by any other sociodemographic variable.

\section{DISCUSSION}

Existing Cochrane reviews do not present evidence on the differential effectiveness of community based tobacco control interventions in different socioeconomic groups. This probably reflects the fact that most primary research has not reported, or sought to establish, how the effects of interventions are distributed between groups. We therefore need to design primary research that aims explicitly to assess the effects of interventions on inequalities, ${ }^{26}$ but if we are to meet new targets for reducing social inequalities in smoking ${ }^{27}$ we also need to extract as much insight as possible from existing evidence. ${ }^{28}$ This might involve extracting stratified data when it is presented in primary studies, encouraging authors to submit additional unpublished analyses, ${ }^{29}$ meta-analyses of individual participant data, or post-hoc reanalysis of original datasets-although the potential for bias in this latter approach is recognised..$^{30}$

In summary, we need further development of systematic review methods (in particular, methods of identifying and synthesising relevant research on health inequalities), and improvements in the reporting of primary studies, to ensure that evidence of differential impacts is not lost. 


\section{What this paper adds}

Most research on the effectiveness of community based tobacco control interventions has focused on achieving overall reductions in smoking, but smoking is closely associated with social disadvantage. We lack good evidence of what interventions are effective in reducing social inequalities in smoking. Systematic reviews are increasingly viewed as the most robust source of evidence of effectiveness, but their utility for answering this important policy question is uncertain.

Existing systematic reviews in the Cochrane Library have either not sought, or not been able to synthesise, evidence to answer this question. Sociodemographic data have been collected on participants in primary studies, but these have not been used to evaluate the differential effectiveness of interventions in different social groups. A new approach to systematic reviewing and/or a re-analysis of existing primary data may be able to contribute new insights from existing evidence to help to identify interventions which are effective in reducing inequalities.

\section{ACKNOWLEDGEMENTS}

The authors are supported by the Chief Scientist Office of the Scottish Executive Health Department, and Mark Petticrew receives funding as part of the ESRC's EvidenceNetwork.

\section{Authors' affiliations}

D Ogilvie, M Petticrew, MRC Social \& Public Health Sciences Unit, University of Glasgow, Glasgow, UK

Correspondence to: Dr David Ogilvie, MRC Social \& Public Health Sciences Unit, University of Glasgow, 4 Lilybank Gardens, Glasgow G12 8RZ, UK; david-o@msoc.mrc.gla.ac.uk

Received 18 March 2003

Accepted 3 October 2003

\section{REFERENCES}

1 Acheson D. Independent inquiry into inequalities in health. London: Stationery Office, 1998.

2 Woodward A, Kawachi I. Why reduce health inequalities? J Epidemiol Community Health 2000:54:923-9.

3 Mackenbach J, Bakker M, eds. Reducing inequalities in health: a European perspective. London: Routledge, 2002.

4 Platt S, Amos A, Gnich W, et al. Smoking policies. In: Mackenbach J, Bakker $M$, eds. Reducing inequalities in health: a European perspective. London: Routledge, 2002.

5 Lancaster T, Stead L, Sowden A, et al. Cochrane Tobacco Addiction Group. In: The Cochrane Library, Issue 4, 2002. Oxford: Update Software.
6 Sowden A, Arblaster L. Community interventions for preventing smoking in young people (Cochrane Review). In: The Cochrane Library, Issue 4, 2002. Oxford: Update Software.

7 Secker-Walker RH, Gnich W, Platt S, et al. Community interventions for reducing smoking among adults (Cochrane Review). In: The Cochrane Library, Issue 4, 2002. Oxford: Update Software.

8 Serra C, Cabezas C, Bonfill X, et al. Interventions for preventing tobacco smoking in public places (Cochrane Review). In: The Cochrane Library, Issue 4, 2002. Oxford: Update Software.

9 Sowden A, Arblaster L. Mass media interventions for preventing smoking in young people (Cochrane Review). In: The Cochrane Library, Issue 4, 2002. Oxford: Update Software.

10 Stead L, Lancaster T. Interventions for preventing tobacco sales to minors (Cochrane Review). In: The Cochrane Library, Issue 4, 2002. Oxford: Update Software.

11 Thomas R. School-based programmes for preventing smoking (Cochrane Review). In: The Cochrane Library, Issue 4, 2002. Oxford: Update Software.

12 Baxter A, Milner P, Hawkins S, et al. The impact of heart health promotion on coronary heart disease lifestyle risk factors in schoolchildren: lessons learnt from a community-based project. Public Health 1997;111:231-7.

13 Biglan A, Ary D, Smolkowski K, et al. A randomised controlled trial of a community intervention to prevent adolescent tobacco use. Tobacco Control 2000;9:24-32.

14 Davidson L. Wensleydale Smokebusters Project Report. Northallerton: Northallerton Health Authority, 1992.

15 Gordon I, Whitear B, Guthrie D. Stopping them starting: evaluation of a community-based project to discourage teenage smoking in Cardiff. Health Educ J 1997;46:42-50.

16 Kaufman J, Jason L, Sawlski L, et al. A comprehensive multi-media program to prevent smoking among Black students. J Drug Educ 1994;24:95-108.

17 Murray D, Perry C, Griffin G, et al. Results from a statewide approach to adolescent tobacco use prevention. Prev Med 1992;21:449-72.

18 Murray D, Prokhorov A, Harty K. Effects of a statewide antismoking campaign on mass media messages and smoking beliefs. Prev Med 1994;23:54-60.

19 Pentz M, Dwyer J, Mackinnon D, et al. A multicommunity trial for primary prevention of adolescent drug abuse. Effects on drug use prevalence. JAMA 1989:261:3259-66.

20 Perry C, Kelder S, Klepp K. Community-wide cardiovascular disease prevention in young people: long-term outcomes of the Class of 1989 Study. Eur J Public Health 1994;4:188-94.

21 Piper D, Moberg D, King M. The Healthy for Life Project: behavioral outcomes. J Primary Prevention 2000;21:47-73.

22 St Pierre T, Kaltreider D, Mark M, et al. Drug prevention in a community setting: a longitudinal study of the relative effectiveness of a 3-year primary prevention program in boys and girls clubs across the nation. Am J Community Psychol 1992;20:673-706.

23 Sussman S, Dent C, Stacy A, et al. One-year outcomes of Project Towards No Drug Abuse. Prev Med 1998;27:632-42.

24 Vartiainen E, Paavola M, McAlister A, et al. Fiffeen-year follow-up of smoking prevention effects in the North Karelia Youth Project. Am J Public Health 1998;88:81-5.

25 Winkleby M, Fortmann S, Rockhill B. Cigarette smoking trends in adolescents and young adults: the Stanford Five-City Project. Prev Med 1993;22:325-34

26 Gowman N, Coote A. Evidence and public health: towards a common framework. London: King's Fund, 2000.

27 Department of Health. The NHS cancer plan: a plan for investment, a plan for reform. London: Stationery Office, 2000.

28 Macintyre S. Evidence based policy making. BMJ 2003;326:5-6.

29 Bowen D, Orlandi M, Lichtenstein E, et al. Intervention effects on youth tobacco use in the community intervention trial (COMMIT). Tobacco Control 2002;11:382.

30 Altman D, Matthews J. Statistics notes: interaction 1: heterogeneity of effects. BMJ 1996;313:486. 